\title{
Response to: Comment on "Factors Associated with Recurrent Ulcers in Patients with Gastric Surgery after More Than 15 Years: A Cross-Sectional Single-Center Study"
}

\author{
Anca Negovan $\left(\mathbb{D},{ }^{1}\right.$ Monica Pantea, ${ }^{1}$ Claudia Banescu $\mathbb{D},{ }^{2}$ and Simona Mocan ${ }^{3}$ \\ ${ }^{1}$ Clinical Science-Internal Medicine, University of Medicine and Pharmacy, Gheorghe Marinescu 38, Tirgu Mureș 540139, Romania \\ ${ }^{2}$ Center for Advanced Medical and Pharmaceutical Research, University of Medicine and Pharmacy, Gheorghe Marinescu 38, \\ Tirgu Mureș, 540139 Mures, Romania \\ ${ }^{3}$ Pathological Department, Emergency County Hospital, Gheorghe Marinescu 50, Tirgu Mures, 540136 Mures, Romania
}

Correspondence should be addressed to Anca Negovan; ancanegovan@yahoo.com

Received 12 September 2018; Accepted 29 October 2018; Published 24 February 2019

Academic Editor: Riccardo Casadei

Copyright ( $) 2019$ Anca Negovan et al. This is an open access article distributed under the Creative Commons Attribution License, which permits unrestricted use, distribution, and reproduction in any medium, provided the original work is properly cited.

We would like to thank Dr. D. Ribaldone and Dr. R. Pellicano for their interest [1] in our article "Factors Associated with Recurrent Ulcers in Patients with Gastric Surgery after More Than 15 Years: A Cross-Sectional Single Center Study" [2]. They raised the problem of false-negative results of Helicobacter pylori (H. pylori) infection in patients with endoscopic lesions. We started the present research after several years of clinical observations in patients with gastric surgery for peptic ulcer disease. The lack of association between mucosal lesions and the most important etiologic factor for ulcer in our population, $H$. pylori infection, determined us to investigate it systematically. Anyway, the results are not very surprising as the clearance of infection occurs in time, after surgery, due to the effect of bile, the progression of atrophic gastritis, intestinal metaplasia, and the gastric $\mathrm{pH}$ changes [3]. In order to rule out a possible confounding factor, we excluded from the beginning the patients with a prior proton pump inhibitor (PPI) or eradication therapy for $H$. pylori, as mentioned in the Method chapter [2]. The biopsies were taken from the very upper part of the corpus, taking into consideration the progression of the topography of gastritis [4]. After standard histochemical staining and examination, when $H$. pylori infection is suggested by the presence of gastritis (active or inactive) or by extensive intestinal metaplasia, the immunohistochemical study is performed. In order to avoid the false-negative results, this approach is routinely used when no organisms are identified, but a high suspicion of infection persists, in accordance with the current recommendation [5]. Using a second test after histological examination could not be an option, as the decreased $H$. pylori load in gastric mucosa may lead to false-negative results in both the stool antigen test and the urea breath test $[6,7]$. One strength of our study is the systematic approach of histologic changes in the gastric remnant. From 76 patients with gastric surgery, only 8 patients $(10.5 \%)$ were $H$. pyloripositive, a low frequency in comparison with our previous reports that found $33 \%-40 \% \mathrm{H}$. pylori-positive patients from consecutive patients investigated on endoscopy $[8,9]$. Nevertheless, the frequency of reactive gastropathy was $73 \%$ among resected patients in comparison with $34 \%$ in our previous series without gastric surgery, supporting the role of chemical aggression in gastric stump, not inflammation [8]. Endoscopic lesions were borderline correlated with low-dose aspirin consumption in our study, and only the small 
number of cases did not allow us to reveal the role of druginduced lesions. Our research aimed to evaluate the influenced factors to avoid long-term complications after gastric surgery and support the diminished role of infection in the studied population.

In conclusion, in patients with long-standing gastric surgery, chemical aggression and reactive gastropathy in gastric mucosa, but not inflammatory changes due to $H$. pylori infection, play a more important role in endoscopic lesion occurrence. In our opinion, the histological examination assessing the cell morphology is the recommended approach to avoid false-negative results for $H$. pylori infection in the research settings.

\section{Conflicts of Interest}

The authors declare that there is no conflict of interest regarding the publication of this article.

\section{References}

[1] D. G. Ribaldone and R. Pellicano, "Comment on "Factors associated with recurrent ulcers in patients with gastric surgery after more than 15 years: a cross-sectional single-center study"," Gastroenterology Research and Practice, vol. 2018, Article ID 8356948, 2018.

[2] M. Pantea, A. Negovan, C. Banescu et al., "Factors associated with recurrent ulcers in patients with gastric surgery after more than 15 years: a cross-sectional single-center study," Gastroenterology Research and Practice, vol. 2018, Article ID 8319481, 8 pages, 2018.

[3] K. Fukuhara, H. Osugi, N. Takada et al., "Correlation between duodenogastric reflux and remnant gastritis after distal gastrectomy," Hepato-Gastroenterology, vol. 51, no. 58, pp. 1241-1244, 2004.

[4] M. Rugge, G. Pennelli, E. Pilozzi et al., "Gastritis: the histology report," Digestive and Liver Disease, vol. 43, no. 4, pp. S373S384, 2011.

[5] P. Malfertheiner, F. Megraud, C. A. O'Morain et al., "Management of Helicobacter pylori infection-the Maastricht V/Florence Consensus Report," Gut, vol. 66, no. 1, pp. 6-30, 2016.

[6] L. Gatta, N. Vakil, C. Ricci et al., "Effect of proton pump inhibitors and antacid therapy on ${ }^{13} \mathrm{C}$ urea breath tests and stool test for Helicobacter pylori infection," The American Journal of Gastroenterology, vol. 99, no. 5, pp. 823-829, 2004.

[7] P. Malfertheiner, "Diagnostic methods for $H$. pylori infection: choices, opportunities and pitfalls," United European Gastroenterology Journal, vol. 3, no. 5, pp. 429-431, 2015.

[8] A. Negovan, M. Iancu, V. Moldovan et al., "Clinical risk factors for gastroduodenal ulcer in Romanian low-dose aspirin consumers," Gastroenterology Research and Practice, vol. 2016, Article ID 7230626, 8 pages, 2016.

[9] A. Negovan, M. Iancu, V. Moldovan et al., "Influence of MDR1 C3435T, CYP2C19*2 and CYP2C19*3 gene polymorphisms and clinical characteristics on the severity of gastric lesions: a case-control study," Journal of Gastrointestinal and Liver Diseases, vol. 25, no. 2, pp. 258-260, 2016. 


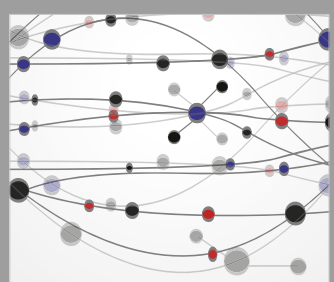

The Scientific World Journal
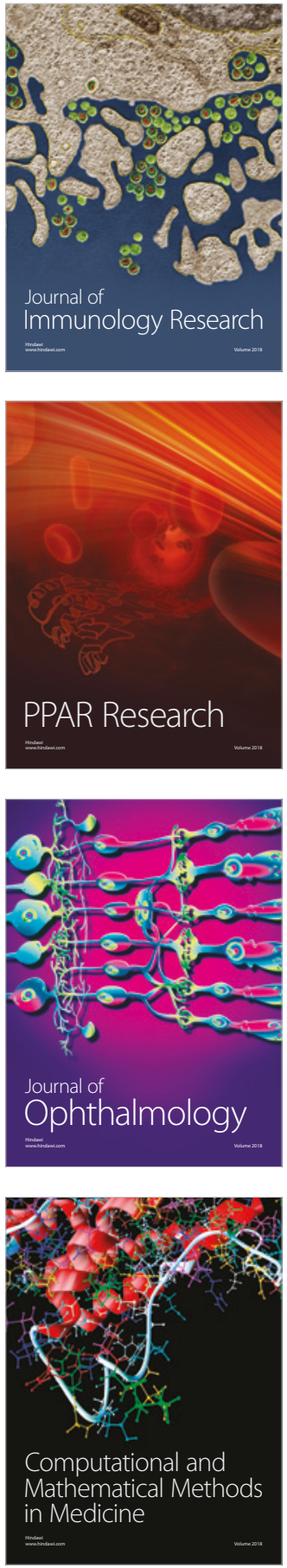

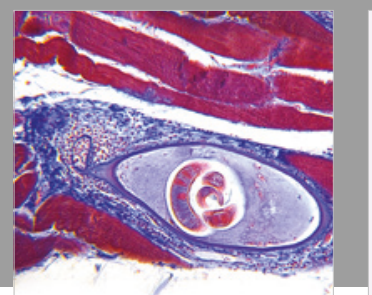

Gastroenterology Research and Practice

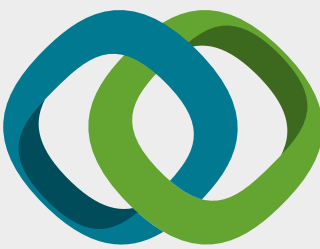

\section{Hindawi}

Submit your manuscripts at

www.hindawi.com
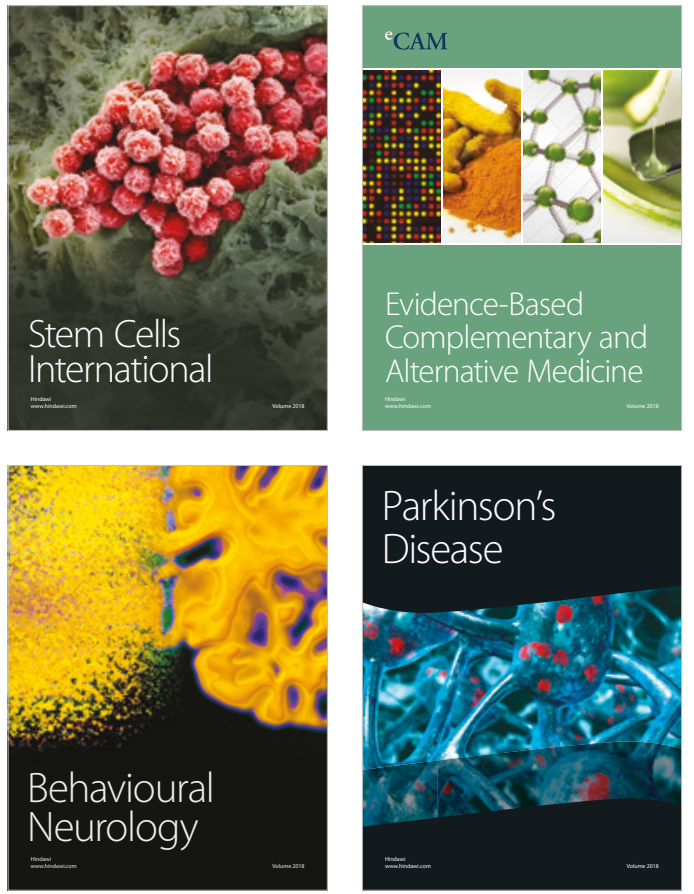

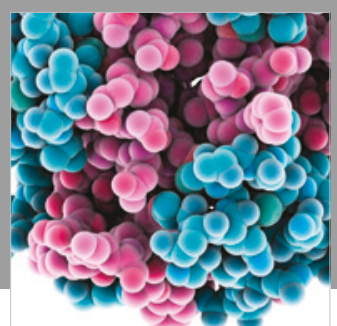

ournal of

Diabetes Research

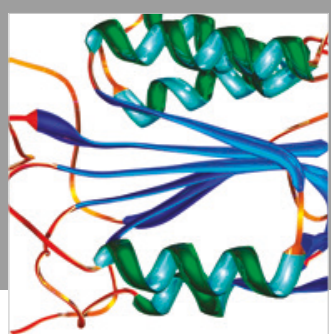

Disease Markers
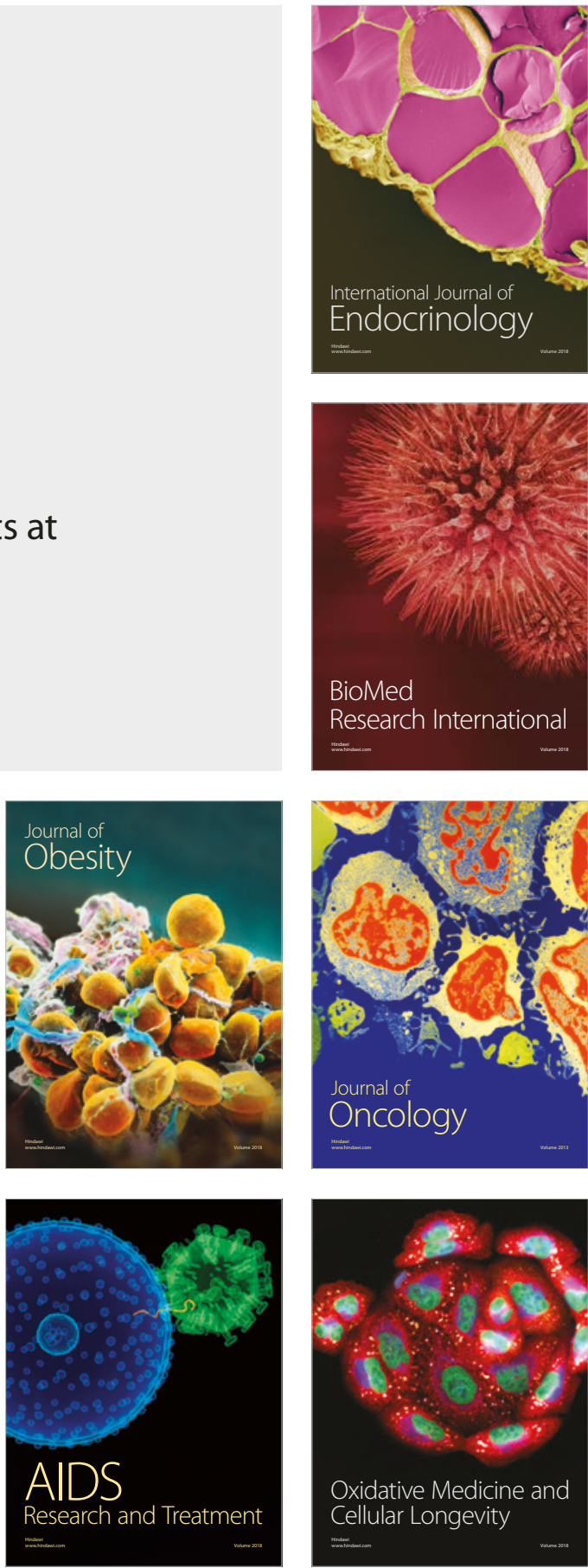